\title{
TERMINOLOGIA E DOCUMENTAÇÃO
}

Maria de Fátima G. M. Tálamo*

RESUMO: Compete à Lingüística Documentária, como disciplina da Documentação, a elaboração de linguagens documentárias efetivamente comprometidas com a recuperaçāo da informação. Reconhece-se, deste modo, que o ato documentário é uma modalidade de comunicação especializada. A garantia do funcionamento comunicacional das linguagens documentárias encontra-se vinculada ao uso da Terminologia como elemento operativo. A interface Terminologia e Lingüistica Documentária institui o lugar da identificação das diferenças entre as unidades de significação - termos e descritores - bem como a contextualização dos espaços de trânsito da informação.

UNITERMOS: documentação; terminologia; lingũistica documentária; linguagem documentária.

ABSTRACT: It is the task of Documentary Linguistics, as a component field of Archive Science, to elaborate documentary languages that effectively target information retrieval. This sums up to the recognition of the documentary act as a form of specialised communication. The guarantee of communicational effectiveness in documentary languages is related to the use of terminology as an operative element. The interface between Terminology and Documentary Linguistics makes up the point where meaning units can be identified - terms and keywords - and provides the context for information exchange.

KEYWORDS: archive science, terminology, documentary Linguistics, documentary language.

- Escola de Comunicaçōes e Artes, Universidade de São Paulo, Brasill.

TradTerm, 7, 2001, p. 141-151 
A Documentação é uma disciplina que se propõe tratar a informação para fins de recuperação. Tem como principio geral garantir o acesso do usuário aos conteúdos informacionais, no menor tempo possivel, com o menor custo. Apresenta-se, nesse sentido, como uma forma de comunicaçāo entre o usuário e os estoques informacionais, representando o conteúdo neles inseridos de forma condensada. Embora evidente, a natureza lingüistica deste processo vem sendo reconhecida tardiamente, o que torna necessária a formulação de quadros adequados para o estudo dos instrumentos de representação da informação, denominados linguagens documentárias. Atualmente a institucionalização do campo da Lingüística Documentária vem ganhando adeptos, pois, ao mesmo tempo que estabelece o principio da natureza simbólica da comunicação documentâria, afirma a necessidade de composição de quadros de referência para a análise, avaliação e construção dessa modalidade de linguagem construida.

O pressuposto inicial da Lingüistica Documentária é o de que a elaboração de linguagens documentárias, bem como a operação com as mesmas, deve fundar-se na sua estrutura organizacional, que considera elementos provenientes tanto dos quadros de produção quanto daqueles dos sistemas cognitivo e comunicativo do usuário. Com isso, reconhece-se de fato que os processos informacionais se realizam em universos simbólicos, cuja constituição procede por mecanismos lógico-lingüisticos e terminológicos, materializando-se em processos comunicacionais socialmente constituidos. Nesse sentido, a linguagem documentária resulta necessariamente de uma hipótese suficientemente pertinente sobre o modo de organização de objetos integrados a conjuntos - enquanto tais, definidos como estoque - para transformálo em fluxo. Em decorrência disso, a transformação do estoque em fluxo depende das formas de proposição das estruturas lingüisticas documentárias.

Tradicionalmente, a linguagem documentária é concebida como um sistema de significaçāo de natureza metalingüistica destinado ao controle de vocabulário. Contraditoriamente, no entanto, a prática documentária se desenvolve de maneira arbitrária na presença muitas vezes de elementos aleatórios que im- 
pedem a avaliação precisa do processo. Alguns manuais de indexação não conseguem mascarar esse fato e, ao mesmo tempo que evidenciam a importância da análise e do tratamento da informação, se restringem a apresentar regras que não definem de maneira objetiva o modo pelo qual se processam as operações lógico-lingüísticas de transformação de um conteúdo em informação.

Vários exemplos tipificam a situação exposta. Alguns manuais, até mesmo normas, apresentam regras de elaboração de resumos relativas apenas à forma que deve ter o produto, imaginando possivelmente que operar com conteúdos seja ato espontâneo. Vocabulários de tradução acompanhados de quadros de referência são tambêm incomuns, o que dá a falsa idéia de que a captação das mensagens - conteúdos registrados - não se realiza em função do universo documentário em interação com o próprio analista.

A mesma situação se repete quando se procuram instrumentalizar as várias interfaces que a Documentação mantém com disciplinas afins na tentativa de formular interpretações que concorram para um conhecimento mais efetivo da própria área. Embora em Lógica instrumental ou aplicada sejam desenvolvidas conceituações relativas à classificação natural e arbitrária, o discente encontra inúmeras dificuldades de associá-las à análise das linguagens classificatórias, principalmente quando, por deslize, seja decorrente da necessidade de atualização, seja decorrente da deformação do método, altera-se o principio classificatório do natural para o arbitrário - o que acarreta a perda do poder representativo da classificação, que passa então apenas a funcionar como sinalização física. Fato semelhante ocorre com a análise da presença desigual de elementos organizadores nas hierarquias. Embora essas ocorrências sejam percebidas, muitas vezes ficam circunscritas à percepção, não integrando sistemas teórico-explicativos, que operam como mediação simplificadora do objeto, que passa então a ser visto como um conjunto de propriedades passivel de interpretações.

O fato, portanto, de a atividade documentária ser observada apenas a partir do seu aspecto prático, isto é, como uma resposta imediata à necessidade de tratar a informação, tem-na impe-

TradTerm, 7, 2001, p. 141-151 
dido de atingir o objetivo natural de toda disciplina, que é a produção de conhecimento. Atribuir-lhe a dimensão teórica não significa, como pode ser eventualmente entendido pelos desavisados, transferir conceitos de áreas afins e passar a trabalhar com nomenclatura, métodos e procedimentos que gozem de prestigio seja no universo acadêmico seja no tecnológico.

De fato, historicamente, a atividade documentária desenvolveu-se de forma empirica. Nesse sentido, os instrumento de tratamento da informação caracterizam-se fundamentalmente por promover a padronização, isto é, substituir um conjunto por uma etiqueta. Essa tarefa desprovida de método contribui de maneira decisiva para a presença de elementos aleatórios no processo, tornando cada ato único, de modo que uma avaliação objetiva não só dos processos documentários mas também dos próprios produtos obtidos encontra-se comprometida. Entre outras coisas, tal situação demonstra que, na ausència de quadros teóricos de referência, a questão empírica não pode se beneficiar de soluções inspiradas em hipóteses e modelos. A reversão desse quadro exige uma alteração de objetivos reais da Documentação, que envolve um projeto efetivo de disciplinarização, com determinação de objeto e métodos próprios.

Além disso, vem se impondo a necessidade de consolidação conceitual da área, já que se instalam de maneira crescente demandas informacionais dos mais variados segmentos sociais. $\mathrm{Na}$ ausência de intervenções adequadas, essas demandas vêm sendo tratadas de maneira precária, sem a presença do profissional da informação. Acrescenta-se a isso o fato de que o tratamento aleatório da informação vem introduzindo o fenômeno da dispersão da informação, denominado por alguns - numa visivel analogia ao caos informacional que provocou o aparecimento da Documentação - de caos documentário, que consiste na impossibilidade ou dificuldade de acesso à informação, ainda que esta esteja estocada e submetida a alguma ordem.

A Análise Documentária constitulu-se como campo de investigação nos anos 60, a partir do reconhecimento de que grandes volumes de informação só poderiam ser convenientemente tratados mediante, por um lado, procedimentos de análise e sintese e, por outro, mediante linguagens construidas para traduzir de 
maneira sintética os conteúdos dos documentos. O grande avanço, contudo, se deu no campo das metodologias de análise e sintese, a partir das quais se reconheceu, por exemplo, a importância das terminologias e das estruturas textuais para a análise da informação, o que redundou no aprimoramento dos procedimentos de tratamento. Pouco se avançou, no entanto, nas propostas de novos produtos documentários ou ainda naquelas relativas aos processos de transferência efetiva da informação. Em parte, isso se deve ao fato de a própria Análise Documentária se propor como disciplina de natureza unicamente metodológica, sem objeto material definido, o que se traduziu na ausência de pesquisas efetivamente dedicadas à elaboração de quadros relativos ao funcionamento simbólico das linguagens documentárias.

Tal situação se explica possivelmente pelo fato de que, embora a noção de linguagem documentária seja tão antiga quanto os primeiros sistemas documentários, sua utilização nem sempre foi acompanhada do rigor necessário (Chaumier, 1978, p. 17). De fato, não está difundida, na área, a consciência efetiva de que os procedimentos documentários se desenvolvem através de linguagem com natureza especifica, responsável por uma ordem significante diferente tanto da linguagem comum quanto da linguagem de especialidade.

Corroborando essa idéia, Garcia-Guttierez (1990), além do próprio Chaumier (1978), afirma que as linguagens documentárias constituem o centro da discussão sobre a análise da informação documentária, pois condicionam efetivamente a qualidade e o valor dos produtos documentários obtidos por tradução.

No conjunto, tais afirmações remetem inevitavelmente à elaboração de interfaces entre a Lingüistica Documentária e a Terminologia, pois desse modo será estabelecida a relação complementar entre dois pontos de vista complementares: o do codificador e o do consumidor da informação. Dito de outro modo, compete à Lingüistica Documentária associar mensagens e contextos.

A construção das mensagens documentárias encontra-se intimamente relacionada à elaboração de sinteses. Acredita-se, de fato, que a linguagem documentária tem a sua origem na elaboração dos enunciados condensados que acompanhavam as for- 
mas mais primitivas de registro. É consenso que a documentação como atividade precede o registro do conhecimento. Documentar é uma operação sobre um conteúdo a que se atribui valor, que se encontra registrado em algum tipo de suporte. A banalidade dessas afirmações impede normalmente uma interpretação global do seu significado. Essa é a tarefa que a seguir nos propomos.

A escrita é considerada a forma mais elementar de registro. Assim, as demais formas compartilham de suas caracteristicas intrinsecas. A escrita não pode ser considerada um fato natural. Surge, possivelmente, como resposta à complexidade crescente da vida social, que redundou na necessidade de acesso às informações pretéritas ou provenientes de outros espaços. De fato, com a escrita, a capacidade da linguagem de traduzir em significados os elementos da vida encontra-se potencializada. Com ela, o pensamento abstrato se desenvolve descontextualizado do mundo imediato. A mensagem escrita, ao contrário da oral, não depende diretamente de quem a propõe nem da quem a recebe. A ela, portanto, agregam-se duas caracteristicas importantes relacionadas à neutralização do tempo e do espaço: a disponibilidade e a permanência.

A partir da sua origem, pode-se afirmar que cabe à atividade documentária articular: necessidades informacionais provenientes da crescente complexidade a que se submete à sociedade apresentando-se a informação como elemento de organização -; formas de mediação, dado o caráter indireto da mensagem, garantindo seu uso social e potencializando a disponibilidade empreendida pela escrita; criação de meios para garantir a permanència promovida pela escrita, seja a perenidade dos conteúdos através de mediatizações contextualizadoras variadas, seja a perenidade do registro através da preservação do suporte.

Com o passar do tempo, as caracteristicas de permanência e disponibilidade da escrita passaram a ter uma convivência contraditória no procedimento documentário. A permanência, por exemplo, redundou em preservação, neutralizando a disponibilidade, que atualmente se enuncia com os termos "circulação da informação", "comunicação da informação" e "transferência da informação”, presentes reiteradamente na literatura. Embora te- 
nha havido um esforço efetivo no sentido de tornar disponiveis os conteúdos dos registros através da elaboração de "enunciados sintéticos", sinalizadores dos conteúdos dos documentos, é possivel que tais enunciados não funcionassem exatamente como mediações. Contribuiu para isso a ausência de uma definição do caráter social da mensagem documentária. De fato, a área se manteve ao largo das discussões sobre o modo de promover as contextualizações necessárias para a circulação de seus produtos, mantendo-se fiel à idéia de uma estrutura universal de organização, válida independentemente dos contextos culturais e das coordenadas espaço-temporais.

Na sua origem, disponibilidade e permanência associam-se à mensagem indireta, pois garante-se a perenidade dos conteúdos tornando-os crescentemente disponiveis. O tratamento do conteúdo, segundo esse entendimento surge como uma operação facilitadora que introduz elementos mediadores necessários para que a disponibilidade se efetive e a perenidade se mantenha como memória atualizada. Para isso, essas mediações não podem ser fruto de operações arbitrárias. Em face da descontextualização introduzida pela escrita, cabem às mensagens mediatizadas - os produtos documentários - recontextualizar os conteúdos segundo situações específicas, ditadas por necessidades de informação. Nesse sentido, a linguagem documentária opera com conteúdos descontextualizados que se apresentam como incógnitas, cuja solução será dada por sucessivas mediações obtidas com a intervenção de linguagens documentárias. Portanto, as linguagens documentárias apresentam-se como estruturas significantes condensadas e contextualizadas.

Qual a natureza dessas contextualizações e como formulálas são questões fundamentais. Pêcheux (1969), por exemplo, trata a questāo associando formação discursiva e formação social, de modo a integrar a transmissão da informação no conjunto dos efeitos de sentido, previsto no funcionamento social da linguagem. Os esquemas de recepção associam-se, então, à posição que o individuo ocupa na sociedade, que não é fixa nem única, mas determinada pelo elenco de papéis que desempenha. Gardin (1968), por sua vez, propõe as especialidades como forma privilegiada de contextualização, uma vez que elas se expressam nor- 
malmente através de vocabulários relativamente estáveis que propiciam a constituição de vocabulários documentários fechados. Para ele, uma linguagem documentária é um conjunto de termos, providos ou não de regras sintáticas, utilizado para representar conteúdos de documentos técnico-científicos com fins de classificação ou busca retrospectiva da informação.

As grandes classificaçōes propõem também contextualizaçōes. Por exemplo, a área de Lingüistica na CDD funda-se na concepção do estudo da linguagem do século XIX, a qual enfatizava a lingüistica histórica e a etimologia. Procurar dar conta da relação entre a lingüistica e a semiótica nesse quadro é uma tarefa difícil, jâ que para isso impõe-se a noção sincrônica da linguagem como atividade. Cobrir o conhecimento parece, portanto, um objetivo inatingivel, já que não é possivel imaginar uma estrutura globalizante que dê conta de processos e etapas do todo.

A tendência hoje verificada da progressiva especialização das linguagens documentárias deve ser entendida como conseqüência, entre outras coisas, da valorização social que experimentam o conhecimento especializado e a formação especializada. A garantia de funcionamento comunicacional da linguagem documentária encontra-se fortemente vinculada ao uso da Terminologia como elemento operativo. São nas fronteiras entre a Terminologia e a Lingüistica Documentárla que se podem identificar as diferenças entre termos e descritores, e a contextualização dos espaços de trânsito da informação, a partir dos quais desenham-se as politicas de informação.

Essas consideraçōes também demonstram que o tratamento da informação não se resume à operação com categorias ideacionais. Esta é uma etapa. O processo só se completa na presença de categorlas textuais, as quals determinam o valor mensagem dos conteúdos. Transformar estoques em fluxos, tarefa da atividade documentária, equivale, então, à afirmação de que aos fluxos não cabe apenas refletir o conteúdo registrado, mas representá-lo de forma socialmente instituida para receptores determinados. Nesse sentido, a informação é estrutura que integra classes Ideacionais e textuais, simultaneamente.

Sob esse ângulo, as linguagens documentárias representam, cada uma a seu modo, um ponto de vista particular da realidade. 
Embora exerçam funçāo normalizadora, sua natureza nāo é a de promovê-la de maneira mecânica. Para compreender esse aspecto, basta observar a lógica das classificações, etapa fundamental na elaboração de instrumentos de representação. Formalmente, as classificaçōes apresentam uma estrutura operatória de conjunto, formada, de um lado, por um encaixe hierárquico de classes e, de outro, por elementos disjuntos obtidos pela introdução de propriedades particulares. Não é mera justaposição de classes elementares, pois comporta, como totalidade, uma estrutura formal própria e leis de composição de conjuntos. Ao operar com um sistema dessa natureza, é preciso analisar o princípio de inclusão e de disjunção das classes, bem como o modo dicotômico de caracterizá-las (equivalência, semelhança, assimetria, transitividade, etc.). Não basta, portanto, apenas observar a existência das relações (base do significado da unidade lingüistica documentária), é preciso reconhecer o princípio subjacente às articulações lógicas para que as mesmas adquiram significado. Caso contrário, a elas será atribuído qualquer significado.

Da forma estrutural depende tanto a extensão quanto a compreensão das classes. No primeiro caso, integram-se continuamente elementos às classes; no segundo, o sistema conceitual entra em jogo para determinar o feixe de traços das unidades, que possiblitam relações diversas entre elas. Neste caso, o entendimento de que as classificações constituem formalizaçōes leva ao equivoco do uso mecânico das mesmas. Se para interpretá-las contribui o sistema conceitual, tem-se, então, que as hierarquias constituem uma operação. São decorrentes de hipóteses de organização do sistema conceitual que as subsume, e não formalizaçōes de uma ordem única e pré-determinada.

Chega-se assim ao que parece ser o fundamental para todo o sistema de organização: a relaçāo é a unidade fundante da estrutura lingüistica documentária e se encontra integrada invariavelmente a um sistema de significação. Não se pode afirmar com rigor o que significa ou o que representa uma unidade observada de maneira isolada. A interpretação pode ser qualquer uma. Essa é de fato a situação usual do trato com a linguagem e que introduz ambigüidades, pois afirma que tratar informação equivale à verbalizá-la. A questão lingüistica a ser respondida consiste sem- 
pre na determinação das relações que a unidade mantém. A relação, em outras palavras, è a fonte da significação, que por sua vez responde pela capacidade de representação da linguagem. A partir daí, as linguagens passam a funcionar exatamente como sistema simbólico. Nesse quadro, a informação define-se pela sua capacidade de integrar estruturas lingüisticas, donde a importância da proposição continua de formas alternativas e diversificadas de estruturas documentárias para responder às necessidades informacionais de segmentos sociais que não sejam reconhecidos como usuários da informação a partir do desenho tradicional da área.

Vale lembrar ainda mais uma vez que no âmbito do simbólico, a organização da informação procede através de hipóteses e não de verdades. Sendo assim, tipologias de informação, tipologias de usuários, tipologias de sistemas, tipologias de linguagens só são úteis e necessárias para uma operação hipotética sobre a realidade que imprime marcas na estrutura lingüística que manifesta a organizaçāo. Nesse sentido, o modelo é que goza de universalidade; os objetos empíricos devem ser avaliados na provisoriedade que lhes é própria.

\section{Referências bibliográficas}

BEGHTOL. C. (1992) Toward a theory of fiction analysis for information storage and retrieval. In: WILLIAMSON, N.J., HUDON, M. (org.) Classification research for knowledge representation: proceedings of the 5th International Study Conference on Classification Research. Toronto, Canadá, June 24-28,1991. Amsterdam, Elsevier.

BRUNET, E. (1992) Le Mot Dictionnaire. Études de linguistique appliqué, n. 85-86, p.34-51.

CHAUMIER, J. (1974) Les techniques documentaires. Paris, PUF.

CHAUMIER, J. (1978) Les langages documentaires. Paris, EME.

CINTRA. A M.M. et al. (1994) Para entender as linguagens documentärias. São Paulo, APB. (Col. Palavra-Chave).

COYAUD, M. (1966) Introduction à l'étude des langages documentaires.

Paris, Klincksieck. (T A. Documents, 1). 
COYAUD, M. (1972) Linguistique et documentation: les articulations logiques du discours. Paris, Larousse.

COYAUD, M., SIOT-DECAUVILLE, N. (1967) L'analyse automatique des documents. Paris, Mounton.

DAHLBERG, I. (1992) The basis of a new universal classification system seen from a science point of view. In: WILLIAMSON, N.J., HUDON, M. (org.) Classification research for knowledge representation and organization: Proceedings of the 5th international Study Conference on Classification Research, Toronto, Canada, June 24-28, 1991. Amsterdam, Elsevier.

GAMBIER, Y. (1991) Travail et vocabulaire spécialisés: prolégomènes à une Socioterminologie. Meta, v. 36, n.1, p.8-15.

GARCIA-GUTIERREZ A. (1990) Suficiencia estructural y tipologia de la omisión en análisis documental. Documentación de las ciencias de la información, n.13, p.73-86.

GARDIN, J.C. (1973) Document analysis and linguistic theory. Journal of Documentation, v. 29, p.137-168.

GARDIN, J.C. (1973) Linguistique et documentation. Bollttino d'Informazioni, 13, n.2/3, p. 67-85.

PÊCHEUX, M. (1969) Analyse automatique du discours. Paris, Dunod.

SMIT, J.W. (1989) (coord.) Análise Documentária: a análise da sintese. 2. ed. Brasilia, IBICT.

TÁLAMO, M.F.G.M. et al. (1992) Contribuição da terminologia para a construção de tesauro. Ciência da Informação, v. 21, n.3, 197-200, set.-dez. 
